\title{
Science INSIGHTS
}

\section{Impact of Epidural Analgesia at Different Cervical Dilation on the Rate of Cesarean Delivery}

Shiqin Xu, Fuzhou Wang, Yusheng Liu, Shanwu Feng, Qingsong Zhao, Xirong Guo, Rong Shen, Hongmei Yuan, Ru Liu, Hua Tong, Xiaoqi Gu, Dongying Fu, Qinfen Pan, Xiaofeng Shen

Science Insights 2014; 7(2):153-166

Science Insights is published by The Bonoi Academy of Science \& Education, Chapel Hill, NC 27510, USA

Copyright (C) 2014 The Bonoi Academy of Science \& Education. All rights reserved.

ISSN: $2329-5856$

The online version of this article, along with updated information and services, is located on the World Wide Web at:

www.bonoi.org

Permissions: Requests for permissions to reproduce figures, tables, or portions of articles originally published in Science Insights can be obtained via our Permission Application System, a service of the Copyright Clearance Center. If you cannot access to this system, you can request permission through toour Editorial Office. Once the online version of the published article for which permission is being requested is located, Request Permissions in the middle column of the Web page under Services. Further information about this process is available in the Permissions and Rights Question and Answer document.

Submission: Information about submission to Science Insights is online at: http://www.bonoi.org/node/74 


\title{
Impact of Epidural Analgesia at Different Cervi- cal Dilation on the Rate of Cesarean Delivery
}

\author{
Shiqin Xu,,,1 Fuzhou Wang,, ,†,1 Yusheng Liu,,,1 Shanwu Feng,,,1 Qingsong Zhao, ${ }^{*}+$ Xirong \\ Guo, " Rong Shen,§ Hongmei Yuan, ${ }^{*}$ Ru Liu, \\ Pan, ${ }^{* *}$ Xiaofeng Shen*,
}

BACKGROUND: Epidural analgesia is the optimal means in controlling labor pain, whereas the correlation between epidural analgesia at different cervix dilation and corresponding risk of operative delivery remains unclear.

OBJECTIVE: The aim of this study was to investigate the association between the epidural analgesia at different cervix and the rate of Cesarean in nulliparous women.

METHODS: This is a perspective controlled trial conducted in a University affiliated tertiary women's health care hospital. After approval by the Institutional Ethical Committee, 780 nulliparous women who underwent spontaneous vaginal delivery at term requesting labor analgesia were screened and 596 of them were assigned into interventions. Subjects were allocated into one of four groups received epidural analgesia initiated at different cervical dilation, i.e. from the onset of painful uterine contraction to the cervix $\mathbf{5 0 . 0} \mathrm{mm}$ or greater. The primary outcome was the rate of Cesarean delivery. Others included maternal and neonatal outcomes due to epidural analgesia and drug delivery.

RESULTS: Five hundred and thirty three subjects completed the study. Significant difference in the rate of Cesarean delivery was observed amongst the four groups (98.9\% at cervix $\leq 10.0 \mathrm{~mm}, 30.2 \%$ at cervix $11.0-30.0 \mathrm{~mm}, 24.2 \%$ at cervix $31.0-50.0 \mathrm{~mm}$ and $18.1 \%$ at cervix $\geq$ $51.0 \mathrm{~mm}, \mathrm{P}<0.0001)$. The major reason led to high Cesarean rate at cervix $\leq 10.0 \mathrm{~mm}$ was poor labor progression (75.2\%). No significant differences were expressed in variables of non-reassuring fetal status. CONCLUSIONS: Epidural analgesia should be avoided in controlling labor pain at the cervix below $10.0 \mathrm{~mm}$ due to its influence on the progress of labor resulting in high rate of Cesarean. Maternal characteristics are additional aspects need to be concerned during epidural labor control in nulliparous women.

TRIAL REGISTRATION: Epidural Analgesia in Different Cervix Diameter and the Rate of Cesarean Delivery (EACDRCD). ClinicalTrials.gov ID, NCT00677274. http://clinicaltrials.gov/ct2/show/NCT00677274.
*:Department of Anesthesiology, Affiliated Nanjing Maternal and Child Health Care Hospital, Nanjing Medical University, Nanjing 210004, China

t:Division of Neuroscience, The Bonoi Academy of Science and Education, Chapel Hill, NC 27510, USA

ף:The Institute of Pediatrics, Affiliated Nanjing Maternal and Child Health Care Hospital, Nanjing Medical University, Nanjing 210004, China

$\S:$ The Department of Obstetrics and Gynecology, Affiliated Nanjing Maternal and Child Health Care Hospital, Nanjing Medical University, Nanjing 210004, China

||:Division of Statistics, Department of Science and Education, Affiliated Nanjing Maternal and Child Health Care Hospital, Nanjing Medical

University, Nanjing 210004, China

**:The Operating Department, Affiliated Nanjing Maternal and Child Health Care Hospital, Nanjing Medical University, Nanjing 210004, China

‡:Present address: Shanghai First Maternity and Infant Hospital, Tongji University School of Medicine, Shanghai, China

||:Present address: McGill University, Montreal, Canada

$\Delta$ :Correspondence to: Dr. Xiaofeng Shen, MD, MPH, Department of Anesthesiology and Critical Care Medicine, Affiliated Nanjing Maternal and Child Health Care Hospital, Nanjing Medical University, No. 123, Tianfei Xiang, Mochou Road, Nanjing 210004, China. Tel: 86-255222-6115, Fax: 86-25-8420-0723 (sxf0418@njmu.edu.cn)

1.These authors contributed equally to this work.

Submitted: 15 November 2013

Revised: 12 February 2014

Accepted: 28 February 2014

SCIENCE INSIGHTS 2014; 7(2):153-166 
How to Cite This Paper: Xu S, Wang F, Liu Y, Feng S, Zhao Q, Guo X, Shen R, Yuan H, Liu R, Tong H, Gu X, Fu D, Pan $Q$, Shen $X$. Impact of epidural analgesia at different cervical dilation on the rate of Cesarean delivery. Science Insights 2014;7(2):153-166.

Keywords: Epidural analgesia - Labor pain - Cesarean - Cervix

$\mathrm{W}$ HILE different people hold different point on how women might cope with the pain from labor, the fundamental is that they should be treated individually. In North America and West Europe (1-4), as well as in China (5-8), epidural analgesia (EA) hitherto is the only available consistently effective technique of pain relief during labor and delivery, and is a preferable method because it can provide more effective pain control compared with non-epidural pharmacological analgesia. However, the timing of EA is a controversial issue. Prior to 2002, clinical guidelines and practitioners considered that the administration of EA in nulliparous women should be delayed until the cervical dilatation reaches at least 4.0 to $5.0 \mathrm{~cm}$ and that other forms of analgesia should be used until that time (9). In 2005, Wong and colleagues published a high-level evidenced paper clarified that pain relief early in labor with neuraxial analgesia at the cervix dilated $\sim 2.0 \mathrm{~cm}$ does not increase the risk of Cesarean delivery (10), and following this is the change in guideline recommendation on EA in labor pain control (11).

The current available evidence, in nulliparous women at term with singleton fetus in vertex presentation, supports that EA is safe in "laboring" women with cervix dilated $2 \mathrm{~cm}$ or more (10). Our previous findings showed that epidural analgesia at the cervix of $1.0 \mathrm{~cm}$ or more is safe for nulliparous women without oxytocin induction (12). In further, systematic reviews on this topic suggest to better define dystocia and non-reassuring fetal status (NRFS) diagnoses by precise and repeatable criteria (13-15). The National Institute for Health and
Clinical Excellence (NICE) guidelines $(16,17)$ suggest that "women in labor who desire regional analgesia should not be denied it, including women in severe pain in the latent first stage of labor - a period of time begins from painful contractions and some cervical change including cervical effacement and dilatation up to $4 \mathrm{~cm}$ ".

When parturients at the cervix below $2.0 \mathrm{~cm}$ request $\mathrm{EA}$, generally, the obstetric care should be integrated with regular and effective uterine contractions, cervical effacement (\%) and rupture of membranes (ROM) timing, and with a favorable cervix evaluated with Bishop Score for an induction or augmentation of labor. Nevertheless, ample evidence from both randomized controlled trials (RCT) and well-designed observational studies suggest pregnant women with induced labor are at higher risk for Cesarean delivery, of which predominantly related to an unfavorable Bishop Score at admission (1820). Under such circumstances, an interdisciplinary team approach and quality assessment is required for successful delivery care. A national wide survey in the United States unraveled that large differences exist in obstetricians' approach to medical decision making with similar patient, and disclosed a real risk for nonevidence-based practice (21). Therefore, written evidence-based protocols are crucial for improving obstetric care outcomes.

Therefore, abundant evidence suggested that early placement of EA at the cervical dilation of $1.0 \mathrm{~cm}$ or more does not increase the risk of Cesarean delivery, but whether the EA performed at cervix below $1.0 \mathrm{~cm}$ could increase the risk of Cesarean or not is yet to be verified, and no study hitherto systematically investigate the influence of EA at different cervix on the rate of operative deliveries. The present study was designed to clarify the relationship between patientcontrolled epidural analgesia (PCEA) administered at different cervical dilation from the onset of labor to the cervix $5.0 \mathrm{~cm}$ or greater and the rate of Cesarean delivery in nulliparous women.

\section{Materials and Methods}

After approval by the Institutional Ethics Examining Committee of $\mathrm{Hu}-$ man Research, 780 nulliparous women who underwent vaginal delivery at term requesting labor analgesia at daytime (from 08:00 AM to 16:00 PM) were screened for eligibility after admission to the labor and delivery unit. A total of 596 subjects met the criteria were assigned to this single-blind and controlled study. All these participants signed an informed consent before initiation of analgesia. Given the potential restriction of cervical dilation, analgesia request and grouping assignment, this study did not do randomization in subjects' enrollment.

A full explanation was given about the technique of epidural puncture and catheterization, the narcotics and local anesthetics used in this study and the linear Visual Analog Scale (VAS) of pain and satisfaction with analgesia. The data were collected from the subjects admitted to the University affiliated tertiary teaching hospital from May to September 2008. Hospital teaching status was ascertained from the Council of Teaching Hospitals of Chinese Medical Colleges. 
Parturients were excluded from the analysis if any of the following criteria were met: a) Allergy to opioids, a history of the use of centrally-acting drugs of any sort, chronic pain and psychiatric diseases records; b) Participants younger than 18 years or older than 45 years; c) Those who were not willing to or could not finish the whole study at any time; d) Parturients with spinal abnormalities, bleeding tendency, infection and anxiety to epidural puncture were not enrolled; e) Alcohol addictive or narcotinum dependent patients were excluded for their influence on the analgesic efficacy of the epidural analgesics; f) Subjects with a nonvertex presentation; g) Diagnosed diabetes mellitus and pregnancy-induced hypertension; h) Twin gestation.

Once subjects were eligible for inclusion, all demographic and clinical data were recorded including age at delivery, weight, height, gestational age of fetus, current status of smoking, VAS rating of pain intensity and vital signs before analgesia, and whether spontaneous rupture of the membrane $>12$ $\mathrm{h}$ before oxytocin infusion (see Appendix 1).

Subjects did not request analgesia or excluded from the study were treated with standard obstetric care procedures according to clinical indications by guideline recommendations (see Appendix 2) (16). The analgesia option was based on individual request and systemic or epidural technique was available to them.

\section{Face Box}

\section{Figure 1. Study Flowchart of the Analgesia Intervention.}

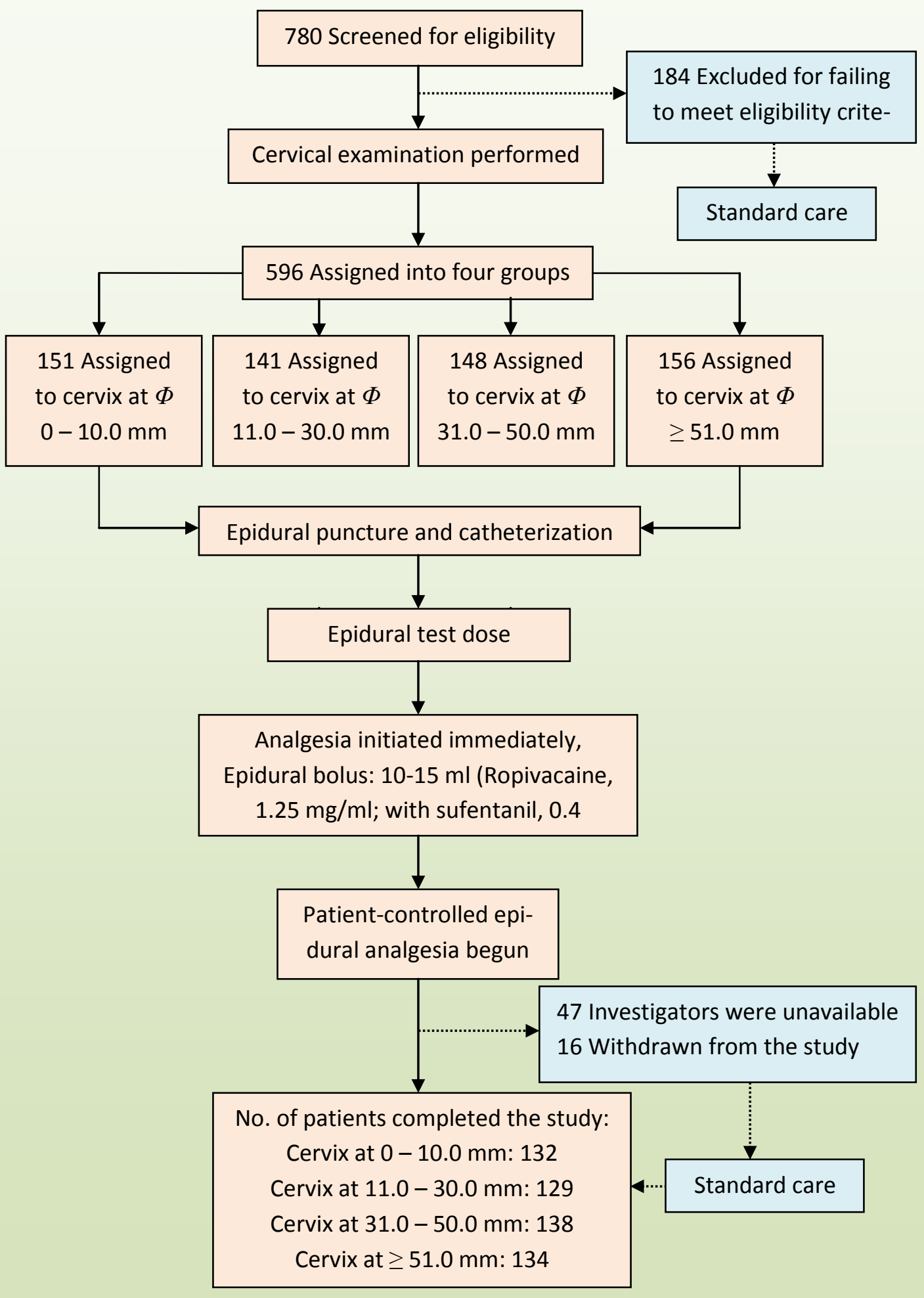

Nulliparous women who underwent vaginal delivery at term requesting labor analgesia were screened for eligibility after admission to the labor and delivery unit. The technique of epidural puncture and catheterization was performed. The test dose of $3.0 \mathrm{ml}$ lidocaine $1.5 \%(45 \mathrm{mg})$ plus epinephrine $5 \mu \mathrm{g} / \mathrm{ml}$ was given. After delivering test dose, an epidural bolus of analgesic mixture $10-15 \mathrm{ml}$ of ropivacaine $0.125 \%$ with sufentanil, $0.4 \mu \mathrm{g} / \mathrm{ml}$, followed by patient-controlled analgesic (PCA) pump with a $5 \mathrm{ml}$ patient-controlled bolus without background infusion, a lockout interval of $15 \mathrm{~min}$ and hourly limit $30 \mathrm{ml} .184$ subjects were screened out from the trial, and the major reasons for exclusion were presented in the result part of the text. 


\section{Table 1. Baseline characteristics of the subjects.*}

\begin{tabular}{|c|c|c|c|c|c|}
\hline \multirow[b]{2}{*}{ Characteristic } & \multicolumn{5}{|c|}{ Cervical Dilation (mm) } \\
\hline & $\begin{array}{l}0-10.0 \\
(n=151)\end{array}$ & $\begin{array}{c}11.0-30.0 \\
(n=141)\end{array}$ & $\begin{array}{c}31.0-50.0 \\
(n=148)\end{array}$ & $\begin{array}{c}\geq 51.0 \\
(n=156)\end{array}$ & $\begin{array}{c}\text { P Val- } \\
\text { ue }\end{array}$ \\
\hline Age at delivery $-\mathrm{yr}$ & $25.5 \pm 3.2$ & $25.0 \pm 5.6$ & $24.9 \pm 4.7$ & $26.1 \pm 5.2$ & 0.97 \\
\hline Weight $-\mathrm{kg}$ & $74 \pm 11$ & $77 \pm 17$ & $69 \pm 10$ & $75 \pm 16$ & 0.91 \\
\hline Height $-\mathrm{cm}$ & $163 \pm 5$ & $159 \pm 9$ & $164 \pm 11$ & $161 \pm 6$ & 0.88 \\
\hline Gestational age of fetus - week & & & & & 0.85 \\
\hline Median & 39 & 38 & 40 & 39 & \\
\hline Interquartile interval & $38-41$ & $37-40$ & $37-41$ & $37-40$ & \\
\hline Current smoker $-\mathrm{n}(\%)$ & $22(14.6)$ & $24(17.0)$ & $17(11.5)$ & $19(12.2)$ & 0.51 \\
\hline $\begin{array}{l}\text { Spontaneous ROM > } 12 \mathrm{~h} \text { before oxytocin infu- } \\
\text { sion }-\mathrm{n}(\%)\end{array}$ & $31(20.5)$ & $36(25.5)$ & $28(18.9)$ & $24(15.4)$ & 0.18 \\
\hline Use of oxytocin prior to analgesia $-\mathrm{n}(\%)$ & $23(15.2)$ & $27(19.1)$ & $17(11.5)$ & $22(14.1)$ & 0.33 \\
\hline \multicolumn{6}{|l|}{ Reasons for oxytocin } \\
\hline Induction of labor after prelabor $\mathrm{ROM}-\mathrm{n}(\%)$ & $14(60.9)$ & $18(66.7)$ & $11(64.7)$ & $15(68.2)$ & 0.96 \\
\hline Augmentation of labor $-\mathrm{n}(\%)$ & $7(30.4)$ & $5(18.5)$ & $4(23.5)$ & $4(18.2)$ & 0.72 \\
\hline Maternal request $-\mathrm{n}(\%)$ & $2(8.7)$ & $4(14.8)$ & $2(11.8)$ & $3(13.6)$ & 0.92 \\
\hline Pain ratings before analgesia with VAS $†$ & & & & & 0.17 \\
\hline Median & 63 & 85 & 87 & 88 & \\
\hline Interquartile interval & $52-77$ & $67-90$ & $70-93$ & $75-97$ & \\
\hline \multicolumn{6}{|l|}{ Vital signs prior to analgesia } \\
\hline \multicolumn{6}{|l|}{ Blood pressure } \\
\hline Systolic pressure $-\mathrm{mmHg}$ & $116 \pm 13$ & $120 \pm 13$ & $109 \pm 12$ & $113 \pm 13$ & 0.76 \\
\hline Diastolic pressure $-\mathrm{mmHg}$ & $65 \pm 7$ & $68 \pm 8$ & $62 \pm 7$ & $73 \pm 9$ & 0.41 \\
\hline Heart rate - beats per minute & $72 \pm 10$ & $71 \pm 5$ & $77 \pm 8$ & $68 \pm 9$ & 0.62 \\
\hline Respiratory rate - breaths per minute & $22 \pm 7$ & $19 \pm 8$ & $23 \pm 5$ & $19 \pm 7$ & 0.84 \\
\hline Oral temperature $-{ }^{\circ} \mathrm{C}$ & $37.3 \pm 0.1$ & $36.9 \pm 0.4$ & $36.8 \pm 0.2$ & $37.0 \pm 0.2$ & 0.16 \\
\hline
\end{tabular}

* Plus-minus values indicate the means \pm standard deviation (SD). P values were calculated with ANOVA or the Chi-square test, as appropriate. $\dagger$ The Visual Analog Scale (VAS) ratings of pain intensity is a 100-point linear gauge in which $0=$ no pain, $100=$ worst pain imaginable. ROM: rupture of membranes.

Even the standard epidural analgesia can be used, yet it was performed by non-study-members, and the corresponding data were not included in analysis.

In our study, we adapted following definitions according to the National Institute for Health and Clinical Excellence (NICE) guidelines on intrapartum care (16): 1) first stage of labor, this consists of latent and active phases in temporal sequence. Latent phase of labor refers to a period of time begins from painful contractions and some cervical change including cervical effacement and dilatation up to $4 \mathrm{~cm}$, and active phase of labor refers to that there are regular painful contractions and progressive cervical dilatation from $4 \mathrm{~cm}$ to fully dilated;
2) second stage of labor, this period begins when the cervix becomes fully dilated $(\sim 10.0 \mathrm{~cm})$ and ends with the complete birth of the infant (22).

All condition-matching subjects underwent cervical examination and then were assigned into one of four groups: group 1 (at cervix $0-10.0$ $\mathrm{mm}$ ), group 2 (at cervix 11.0-30.0 $\mathrm{mm}$ ), group 3 (at cervix 31.0-50.0 $\mathrm{mm}$ ) and group 4 (at cervix $\geq 51.0$ $\mathrm{mm})$. Parturients and healthcare providers who did not involve in this trial as study members were kept from group allocation. Study investigators were opened to group assignment, data collection and results analyses. The technique of epidural puncture and catheterization was performed to all participants. The test dose of $3.0 \mathrm{ml}$ lidocaine $1.5 \%$ (45 mg) plus epinephrine $5 \mu \mathrm{g} / \mathrm{ml}$ was given to patients. After delivering test dose, all participants immediately received an epidural bolus of analgesic mixture $10-15 \mathrm{ml}$ of ropivacaine $0.125 \%$ $(1.25 \mathrm{mg} / \mathrm{ml})$ with sufentanil, 0.4 $\mu \mathrm{g} / \mathrm{ml}$, followed by patient-controlled analgesic (PCA) pump with a $5 \mathrm{ml}$ patient-controlled bolus without background infusion, a lockout interval of $15 \mathrm{~min}$ and hourly limit $30 \mathrm{ml}$.

The maternal parameters monitored during the whole study from before the analgesic procedures to the completion of the labor including the heart rate by 5-lead electrocardiograph, respiratory rate, noninvasive systolic and diastolic blood pressure, 
Figure 2: Rate of Cesarean Delivery in Relation to the Absolute Cervical Dilation during Epidural Analgesia.

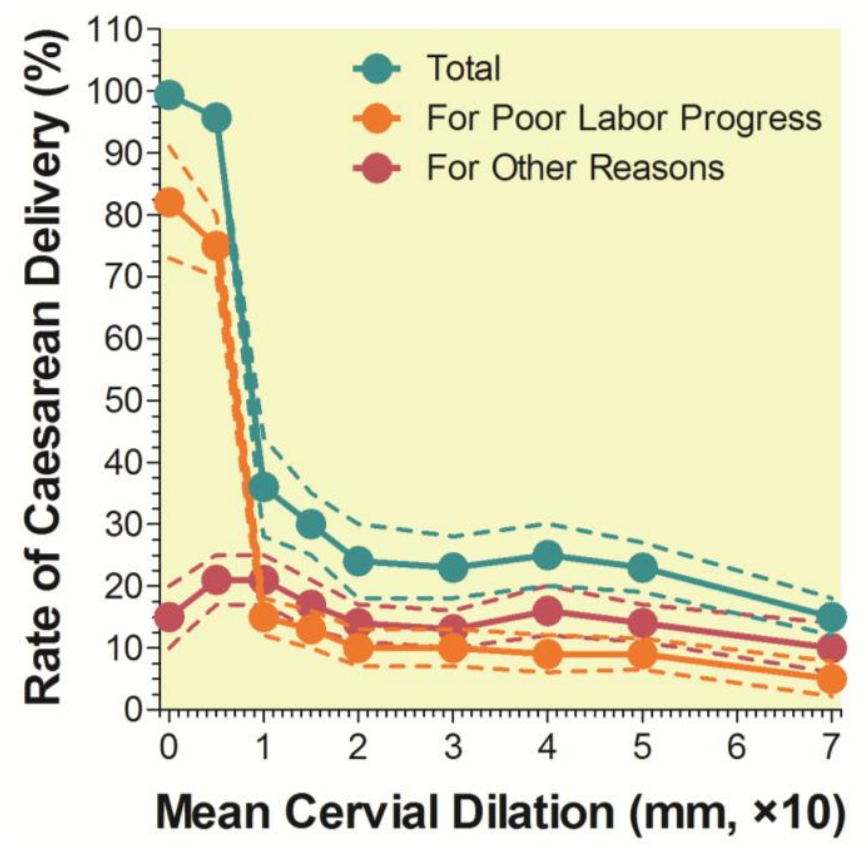

Data are presented as mean \pm SD of the Cesarean delivery.

mean arterial pressure and fingertip pulse oximetry.

A catheter was inserted in a right or left antecubital vein for fluid and drug administration. Ringer's solution $8 \mathrm{ml} / \mathrm{kg}$ was titrated 15 minutes prior to initiation of EA. Intrapartum fluid management included replacement of preexisting fluid deficits, normal losses (maintenance requirements), the amount of urine collected via a measurable basin-like container, and hemodynamic variables.

The intrauterine pressure sensor, if necessary, was placed to show the intensity of uterine contraction. Oxytocin was infused by the nursing staff set by the obstetricians according to clinical guidelines (detailed criteria and procedures see Appendix 1). A decision whether an operative delivery need to be proceeded to was made by the obstetrical team who did not involved in this study depending upon maternal and fetal indications (see Appendix 2).

During the whole process of study, the patient-derived VAS scores of pain at rest were measured hourly with the 100-mm gauge (based on a 0-100 linear VAS, $0=$ no pain; $100=$ worst pain imaginable). Global pain to each patient, namely the pain intensity on average the patient felt during labor, was scored. In addition, the maternal satisfaction with analgesia was assessed via the VAS system (a 1-100 mm linear VAS used, $1=$ dissatisfaction; 100 = fully satisfied). Finally, the incidence of the side effects, such as nausea, vomiting, pruritus, shivering and urinary incontinence or retention throughout the study were recorded by the follow-up physicians according to the maternal reports; maternal oral temperature and hypotension were measured by caregiver intermittently.

A continuous external electronic fetal heart-rate monitoring and tocodynamometry were made. Apgar scores were rated by the pediatric personnel according to the standard assessment. Umbilical-cord blood gas analysis was performed by the investigators.
The rate of operative delivery was selected as the primary outcome. In addition, the Odds Ratios of the interventional variables were calculated and recorded as supplementary data to the primary outcome. The following measures were selected as the secondary outcomes: the indication for Cesarean delivery; the rate of instrumental delivery; the time from the randomly allocation of groups to performing EA procedures; the interval from the initiation of EA to the time of a decision of CS was made; the time from the onset of painful uterine contraction to completion of vaginal delivery; the duration of EA; the verbal ratings of VAS pain and satisfaction with analgesia; oxytocin requirements; the maternal oral temperature; the incidence of side effects from epidural puncture and drug administration; infant outcomes, such as the body weight, Apgar scorings, umbilical-cord blood gas measurement and antibiotic treatment.

Neonatal sepsis evaluation was performed as previously reported (23). In brief, a blood culture and a complete blood count of the neonate suspected for sepsis possibility performed and followed by a lumbar puncture if one major or two minor criteria presented at the time of the study. Major criteria included rupture of membranes for $>24 \mathrm{~h}$ or a sustained fetal heart rate of $>160$ beats per minute lasted up to 15 minutes or longer. Minor criteria included a lowgrade maternal temperature of $37.5^{\circ} \mathrm{C}$ to $38^{\circ} \mathrm{C}$, rupture of membranes for 12 to $24 \mathrm{~h}$, maternal admission white blood cell count of $>15,000$ cells $/ \mathrm{ml}^{3}$, or five-minute Apgar score $<7$.

\section{Statistical analyses}

Analyses were performed using GraphPad Prism v5.0 (GraphPad Software Inc., San Diego, CA, USA). Values are expressed as the mean, standard deviation (SD), median, interquartile interval, Odds Ratio (OR) or numbers. A pre-study power table where $\delta$ (the mean difference in $\mathrm{Ce}$ - 
Table 2. Primary and secondary outcomes. *

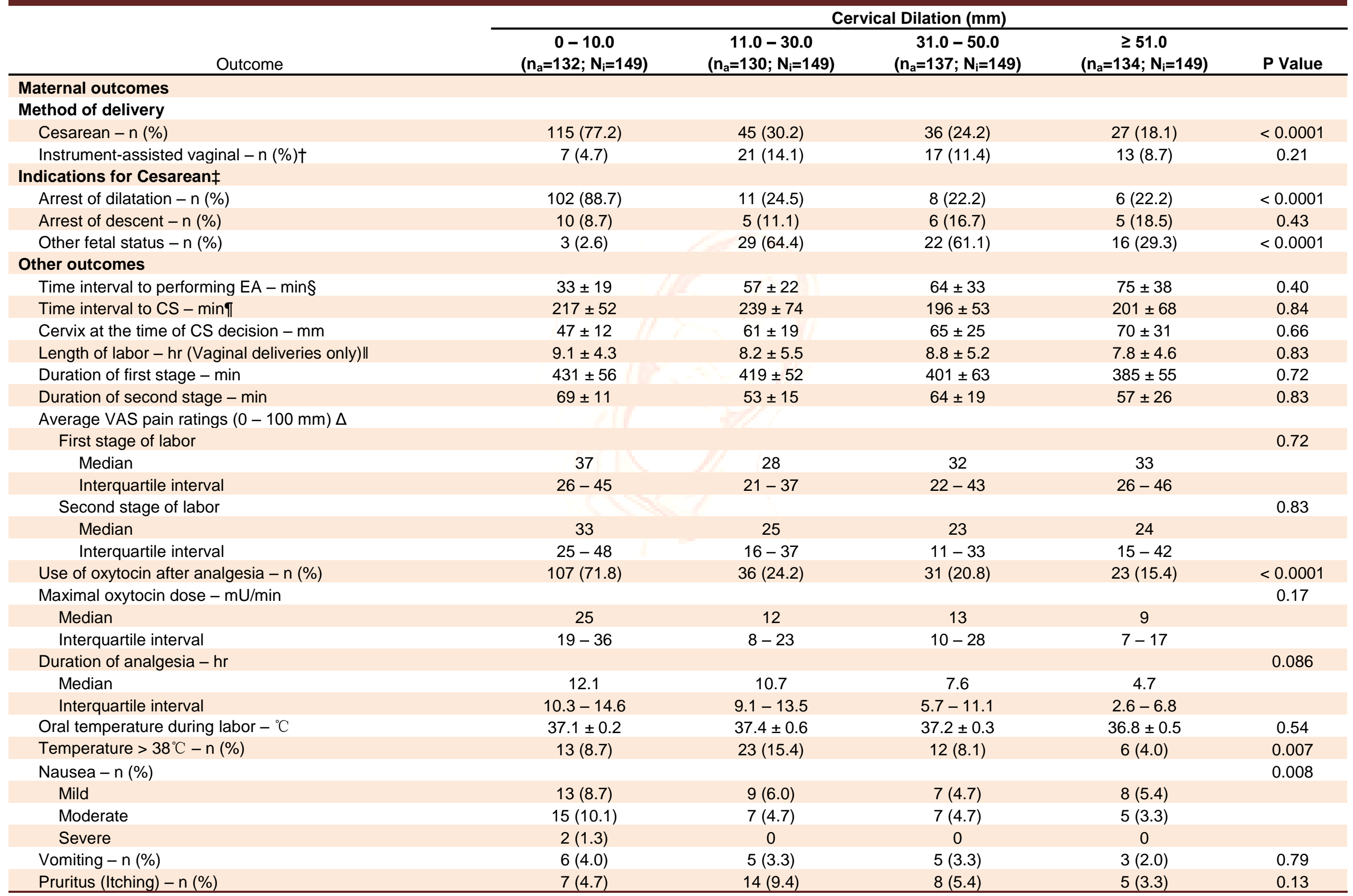




\begin{tabular}{|c|c|c|c|c|c|}
\hline Urinary retention - $\mathrm{n}(\%)$ & $2(1.3)$ & $3(2.0)$ & $1(0.7)$ & 0 & 0.11 \\
\hline Urinary incontinence $-\mathrm{n}(\%)$ & 0 & $1(0.7)$ & 0 & 0 & 0.39 \\
\hline Shivering $-\mathrm{n}(\%)$ & $11(7.4)$ & $17(11.4)$ & $6(4.0)$ & $4(2.7)$ & 0.01 \\
\hline Hypotension - n (\%) & 0 & $1(0.7)$ & 0 & 0 & 0.39 \\
\hline Highest sensory block & $\mathrm{T} 8(\mathrm{~T} 7-\mathrm{T} 12)$ & T9 (T8 - T11) & T9 (T8 - T12) & $\mathrm{T} 8(\mathrm{~T} 7-\mathrm{T} 12)$ & 0.90 \\
\hline \multicolumn{3}{|c|}{ Maternal overall satisfaction score with analgesia (VAS, $1-100 \mathrm{~mm})$ ** } & & & 0.085 \\
\hline Median & 46 & 85 & 74 & 61 & \\
\hline Interquartile interval & $35-58$ & $63-95$ & $52-83$ & $43-72$ & \\
\hline \multicolumn{6}{|c|}{ Non-reassuring fetal status (NRFS) birthed vaginally $\dagger^{\dagger}$} \\
\hline Weight - g & $3500 \pm 336$ & $3455 \pm 352$ & $3568 \pm 476$ & $3469 \pm 445$ & 0.93 \\
\hline $1-\min$ Apgar $<7-\mathrm{n}(\%)$ & $4(23.5)$ & $19(22.3)$ & $15(14.8)$ & $12(11.2)$ & 0.19 \\
\hline $5-\min$ Apgar $<7-\mathrm{n}(\%)$ & 0 & 0 & 0 & 0 & - \\
\hline Umbilical - cord gases measured - n (\%) & $15(88.2)$ & $77(90.6)$ & $81(80.2)$ & $84(78.5)$ & 0.12 \\
\hline Umbilical - vein pH & $7.32 \pm 0.03$ & $7.30 \pm 0.04$ & $7.28 \pm 0.05$ & $7.27 \pm 0.06$ & 0.72 \\
\hline Umbilical - artery pH & $7.22 \pm 0.04$ & $7.20 \pm 0.03$ & $7.21 \pm 0.05$ & $7.22 \pm 0.03$ & 0.88 \\
\hline Low umbilical cord $\mathrm{pH}($ artery $<7.20)-\mathrm{n}(\%)$ & $10(58.8)$ & $46(54.1)$ & $32(31.7)$ & $26(24.3)$ & $<0.0001$ \\
\hline Neonatal antibiotic treatment $-\mathrm{n}(\%)$ & $3(17.6)$ & $16(18.8)$ & $15(14.8)$ & $11(10.3)$ & 0.39 \\
\hline
\end{tabular}

* Plus-minus values are means \pm standard deviation (SD). P values were calculated with ANOVA, the Kruskal - Wallis test or the Chi-square test, as appropriate.

$\dagger$ The percentage was calculated with the number of subjects need instrumental delivery to the intent-to-treat number of participants.

$\ddagger$ The percentage was calculated with the number of subjects indicating to need Cesarean section to the total number of participants had Cesarean delivery.

$\S$ Time interval to performing EA refers to the period from the randomly allocation of group to performing EA procedures.

I Time interval to CS refers to the period from the initiation of EA to the time of a decision of CS was made.

IIThe length of labor indicates the time period from the onset of regular uterine contraction to the $1 \mathrm{hr}$ after delivery of placenta.

$\triangle$ The VAS system of pain is a 0 to $100 \mathrm{~mm}$ linear gauge in which $0=$ no pain, $100=$ worst pain imaginable.

** The VAS system of satisfaction with analgesia is a 1 to $100 \mathrm{~mm}$ linear gauge in which 1 = dissatisfaction, $100=$ fully satisfied.

†† The percentage was calculated through the number of neonates with positive outcomes to all babies birthed vaginally.

$\mathrm{n}_{\mathrm{a}}$ : The actual number of patients who completed the study; $\mathrm{N}_{\mathrm{i}}$ : the intention-to-treat number of patients; EA: epidural analgesia; CS: Cesarean section. 


\section{Figure 3: Proportion of Cesarean Delivery in Relation to Overall Outcome Characteristics in}

\section{Different Cervical Dilation during Epidural Analgesia.}

A

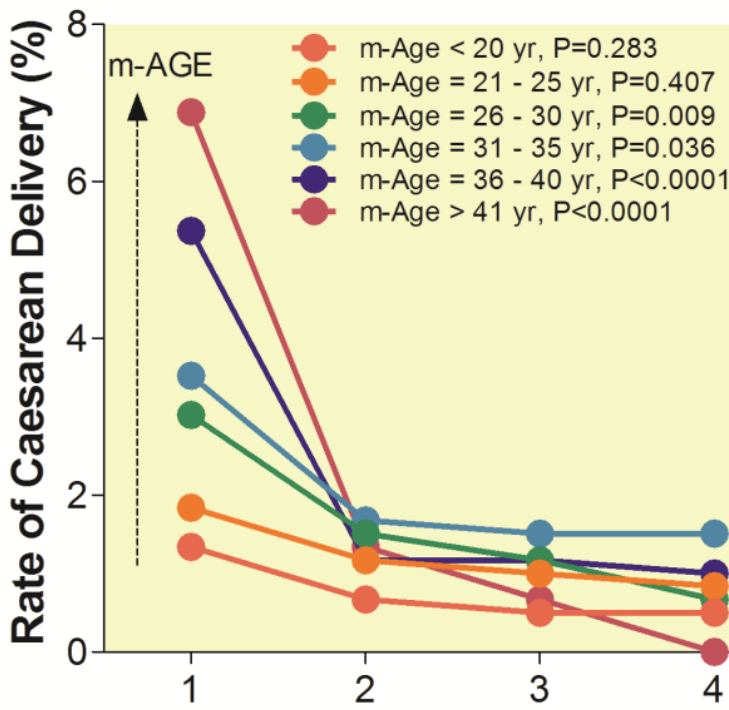

Cervix(cm)

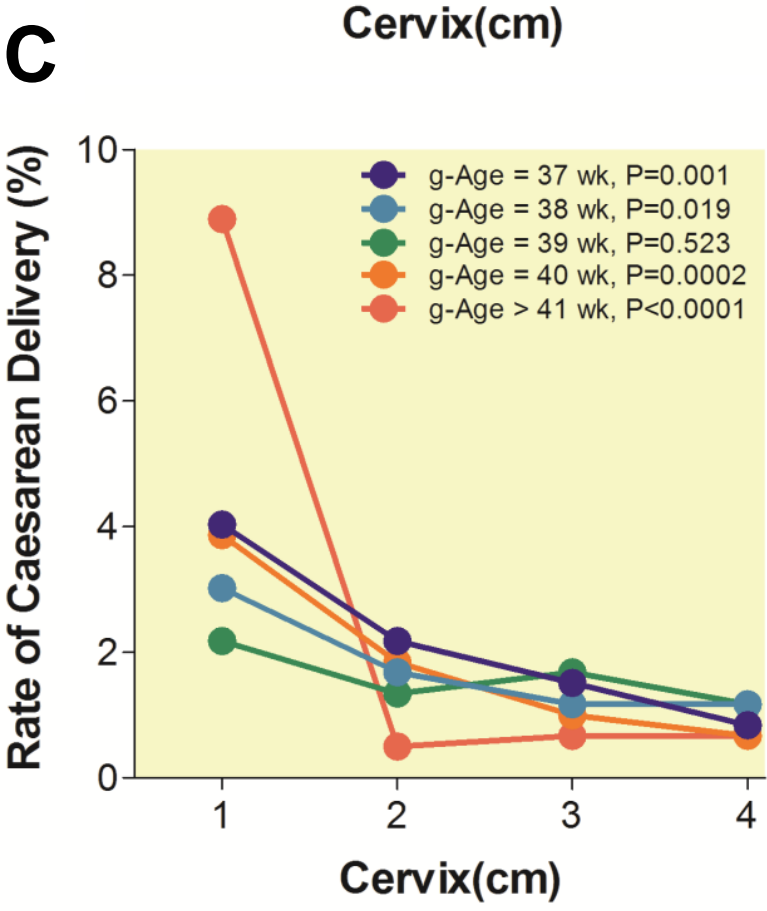

B

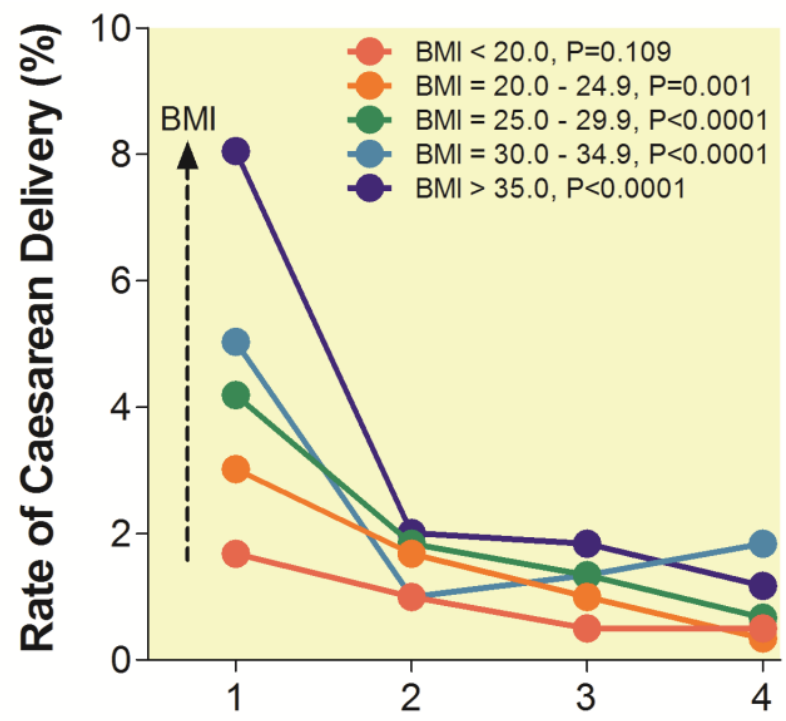

D

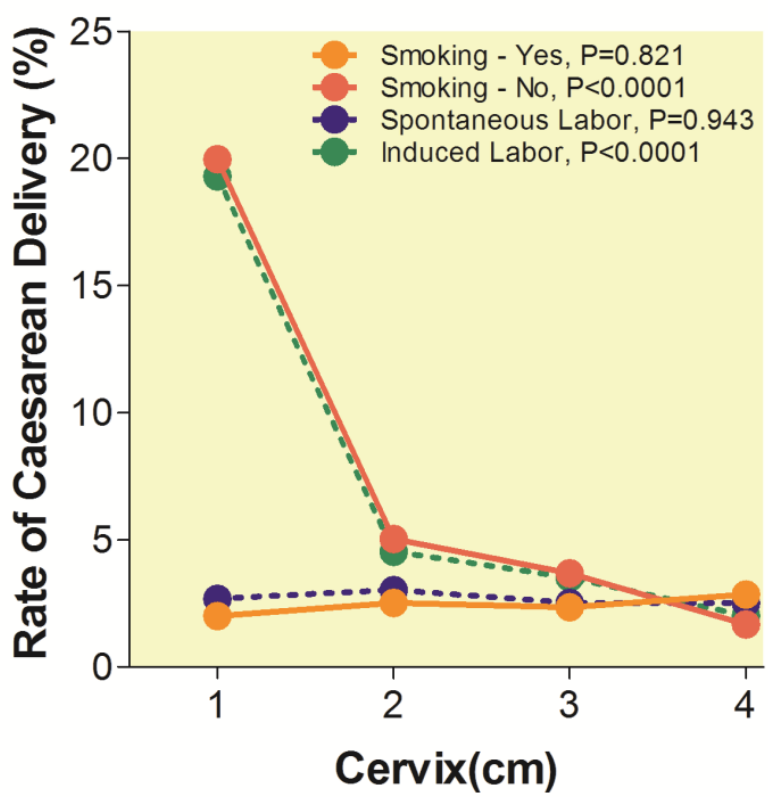

The correlation amongst the maternal characteristics and the rate of Cesarean section was analyzed. Panel $A$ is the maternal age at delivery, in which the arrow denotes the CS rate at the cervix $\leq 10.0 \mathrm{~mm}$ group increased with the increase of maternal age. Panel $B$ is the maternal body-mass index (BMI), in which the arrow denotes the CS rate at the cervix $\leq 10.0 \mathrm{~mm}$ group increased with the increase of maternal BMI. Panel $\mathrm{C}$ is the gestational age at birth, in which the gestational age $>40$ weeks or $<39$ weeks is risk factor for the CS. Panel $D$ is the smoking status and means of labor, in which smoking during pregnancy does not increase the rate of CS, but the induced labor are one confounder influencing the rate of CS. 
sarean delivery about 41 percent in four groups recorded in a pilot study), the rate of CS was $71 \%$ in the group at cervix $\leq 10.0 \mathrm{~mm}$, and $30 \%$ in other groups at cervix $\geq 11.0 \mathrm{~mm}$; expected SD was 1 ; two-sided $\alpha=0.05$, one-sided $\beta=0.10$ and the power of test $=0.90$, resulted in the need for a minimum of 125 subjects in each group to detect this difference. In preventing potential missing data during following-up, therefore, the intention-to-treat number of patients was increased to 149 to each group. However, our early observation showed that round thirty per cent patients would be dropped-out during the screening period, so we increased the screening size of patients to 195 to each group to account for potential drop-outs.

All categorical data were analyzed with a Chi-square test or Fisher's exact test to indicate the trend. Continuous variables like as the effects of the epidural analgesia on patient's self-rated VAS of pain and satisfaction, the duration of labor and each stage of delivery, and the highest sensory block level were summarized by calculating the median and interquartile interval, and compared with the Kruskal-Wallis test. The demographic data and background characteristics were presented as mean \pm SD and analyzed with one-way analysis of variance (ANOVA). The ANOVA tests were always followed by the Bonferroni post hoc tests. To identify the characteristics associated with the Cesarean delivery, the binary logistic regression analysis was used for the primary outcome. All reported P values are two-sided and a $\mathrm{P}$ value of equal or less than 0.05 was considered to indicate statistical significance.

\section{Results}

Seven hundred and eighty gravidas were screened for eligibility (Fig. 1). Five hundred ninety six subjects were assigned to the four groups and followed up. The intention-to-treat number of patients was one hundred forty nine in each group. Finally, forty seven $(7.9 \%)$ were excluded after group assignment because follow-up physician's unavailable and consequently this investigator was ruled out from the study group, and sixteen patients $(2.7 \%)$ withdrawn from the trial without clear reasons. Finally, five hundred thirty three subjects totally completed the whole study. As a result, the data from these sixty three women enrolled but not completed the study after assignment was unable to be evaluated in the same fashion as the other participants. They were not included in the analysis of completed patients' data but in the intention-totreat analysis. We excluded one hundred and eighty four records during screening period because of the following reasons of which are likely to overlap each other: 88 (47.8\%) were nonvertex presentation; 47 (25.5\%) diagnosed with diabetes and pregnancy-induced hypertension; 17 (9.2\%) were twin gestation; 16 (8.7\%) were not in the inclusion range of age (18 to 45 years) at delivery; 11 (5.9\%) refused to participation; $9(4.9 \%)$ were alcohol addictive; 3 (1.6\%) had history of the use of centrally-acting drugs.

The material from all subjects underwent assignment was analyzed for baseline characteristics. There were no significant differences in the demographic and background data amongst the four groups (Table 1). Vital signs all were within the physiological ranges throughout the analgesic period and not significantly different among the groups. In this trial, the average duration of performing EA procedures was $8 \pm 3 \mathrm{~min}$ in all participants. There was no statistically significant difference observed in EA performing duration among the four groups.

The results were displayed by analyzing the material depending on the intention-to-treat number of patients, but not the actual number of patients completed the study. Big difference in the rate of Cesarean delivery was shown in the four groups, the difference in the CS rate at the cervix $\leq$
$10.0 \mathrm{~mm}$ compared with other three groups was at least 57.7 percentage points or greater $(\mathrm{P}<0.0001$, Table 2 , Fig. 2). The indications of Cesarean delivery showed big differences amongst groups, especially in the arrest of cervical dilation $(\mathrm{P}<0.0001$, Table 2). In addition, the percentages of subjects who obtained oxytocin infusion after analgesia still expressed significant difference $(\mathrm{P}<$ 0.0001 , Table 2). If took the analgesia at cervix $11.0-30.0 \mathrm{~mm}$ as the referent of CS, the ORs were 16.82 , 0.71 and 0.51 in the cervix $\leq 10.0$ $\mathrm{mm}, 31.0-50.0 \mathrm{~mm}$ and $\geq 51.0 \mathrm{~mm}$ groups, respectively (Table 3 ).

We analyzed the data via a multivariate regression to assess the association between the baseline variables and the rate of Cesarean deliveries, and to clarify the confounders related with the CS rate during epidural analgesia. Maternal age at delivery and body-mass index (BMI), gestational age at labor, smoking status and onset of labor were evaluated, and found that maternal age and BMI are two confounders positively associated with the increase of CS rate at the cervix $\leq 10.0 \mathrm{~mm}$. Moreover, gestational age $>40$ weeks or $<39$ weeks and induced labor are risk confounders for CS rate during EA at the cervix $\leq 10.0 \mathrm{~mm}$. But smoking status is not in association with the increased rate of CS (Table 3, Fig. 3).

There were no significant differences in the length of vaginal labor, the time to the first and second stages of labor (Table 2). The average VAS ratings of pain prior to analgesia were similar, $\mathrm{P}=0.17$. There were no significant differences in the VAS pain scorings after analgesia (Table 2). The duration of analgesia in both groups was calculated from the bolus injection of the drug mixture into epidural space to the disappearance of the sensory block. The analgesic time shortened with the delayed beginning of EA at different cervical dilation, but no significant difference was observed, $\mathrm{P}=0.086$ (Table 2).

The intrapartum nausea, shivering and oral temperature $>38^{\circ} \mathrm{C}$ ex 


\section{Table 3: Odds ratios for caesarean delivery. *}

\begin{tabular}{|c|c|c|}
\hline Variable & Odds Ratio $(95 \% \mathrm{Cl})$ & $P$ Value \\
\hline \multicolumn{3}{|l|}{ Cervical dilation - $\mathrm{mm}$} \\
\hline $0-10.0$ & $16.82(9.19-30.78)$ & $<0.0001$ \\
\hline $11.0-30.0$ (Referent) & 1.0 & \\
\hline $31.0-50.0$ & $0.74(0.44-1.23)$ & 0.24 \\
\hline$\geq 51.0$ & $0.51(0.29-0.88)$ & 0.015 \\
\hline \multicolumn{3}{|l|}{ Age at delivery $-\mathrm{yr}$} \\
\hline$\leq 20$ & $0.46(0.26-0.81)$ & 0.006 \\
\hline $21-25$ & $0.75(0.45-1.23)$ & 0.26 \\
\hline $26-30$ (Referent) & 1.0 & \\
\hline $31-35$ & $1.31(0.84-2.04)$ & 0.22 \\
\hline $36-40$ & $1.40(0.91-2.17)$ & 0.12 \\
\hline$>40$ & $1.43(0.93-2.21)$ & 0.10 \\
\hline \multicolumn{3}{|l|}{ Body-mass index (BMI) } \\
\hline$<20.0$ & $0.59(0.35-1.03)$ & 0.059 \\
\hline $20.0-24.9$ (Referent) & 1.0 & \\
\hline $25.0-29.9$ & $1.36(0.87-2.13)$ & 0.17 \\
\hline $30.0-34.9$ & $1.58(1.02-2.44)$ & 0.038 \\
\hline$>35.0$ & $2.34(1.55-3.54)$ & $<0.0001$ \\
\hline \multicolumn{3}{|l|}{ Gestational age at birth - week } \\
\hline 37 & $1.17(0.77-1.78)$ & 0.45 \\
\hline 38 & $0.95(0.61-1.47)$ & 0.82 \\
\hline 39 & $0.85(0.54-1.34)$ & 0.49 \\
\hline 40 (Referent) & 1.0 & \\
\hline$>41$ & $1.51(1.01-2.25)$ & 0.044 \\
\hline \multicolumn{3}{|l|}{ Current smoker } \\
\hline Yes & $0.25(0.18-0.34)$ & $<0.0001$ \\
\hline No (Referent) & 1.0 & \\
\hline Onset of labor & & \\
\hline Spontaneous (Referent) & 1.0 & \\
\hline Induced & $3.45(2.52-4.73)$ & $<0.0001$ \\
\hline
\end{tabular}

* Calculated according to the global outcome characteristics.

pressed significant differences amongst the groups. No significant difference was observed in the other side effects like as vomiting, pruritus, urinary incontinence and retention, hypotension as well as motor block (Table 2).

There were no significant differences in Apgar scorings, umbilicalcord $\mathrm{pHs}$, incidence of sepsis and antibiotic use. The occurrence of umbilical artery $\mathrm{pH}<7.20$ increased when the EA was performed in the earlier labor $(\mathrm{P}<0.0001$, Table 2$)$.

We got similar results in actual per patient analyses as well as the intention-to-treat analyses presented as the above ones.

\section{Discussion}

The data of this trial demonstrate that epidural labor analgesia at the cervi- cal dilation $\leq 10.0 \mathrm{~mm}$ is a risk in resulting in intrapartum Cesarean delivery, during which the maternal age at delivery and BMI, gestational age at labor and induced labor are confounding factors in influencing the CS rate. Nevertheless, the EA technique at the cervix $>10.0 \mathrm{~mm}$ is an effective and safety means in controlling labor pain without increasing the rate of Cesarean delivery in nulliparous women (12).

We systematically investigated the correlation between the EA performed at different cervix dilation and the rate of $\mathrm{CS}$, and the results extended current knowledge with respect to the minimal cervix needed to get epidural labor control. Wong and colleagues have compared the risk of Cesarean delivery after early neuraxial analgesia (CSEA) vs. systemic analgesia given at the cervix
$<4.0 \mathrm{~cm}$, in which the cervical dilation reached $\sim 2.0 \mathrm{~cm}$ (10). Chestnut's studies actually belonged to the active phase analgesia intervention (24, 25). In the present study, we performed EA from the onset of painful uterine contraction to the cervical dilation $>50.0 \mathrm{~mm}$, and big difference in the CS rate was found when the cervix $\leq 10.0 \mathrm{~mm}$. As thus the interventional window of epidural labor analgesia in nulliparous women can be enlarged from $20.0 \mathrm{~mm}$ to $10.0 \mathrm{~mm}$ of cervical dilation as presented by our previous study (12).

While Wong found that intrathecal opioid use significantly shortened the first stage of labor compared with the systemic opioid administration (10), in the present trial, no significant difference was gotten in the duration of vaginal labor, the time to first and second stage of delivery, which was 
likely to be the reason that the data from the group at cervix $\leq 10.0 \mathrm{~mm}$ were excluded in data analyses. It suggests the earlier initiation of epidural analgesia at cervix $>10.0 \mathrm{~mm}$ in nulliparous women is not a risk factor for prolonging the progress of labor. Nonetheless, one major finding in this study is that the increased rate of CS in at the cervix $\leq 10.0 \mathrm{~mm}$ patients was mainly because of the influence of EA on the progression of labor, and correspondingly, more oxytocin was prescribed to them for poor labor progress. These are in agreement with other reports that an association existed between EA and intrapartum oxytocin infusion (26), and the EA combined with oxytocin infusion would increase the rate of CS (27).

Our results are consistent with previous studies the rate of instrumental deliveries would be increased if the epidural infusion of local anesthetics lasted longer $(28,29)$. When the EA performed at the cervical dilation $>10.0 \mathrm{~mm}$, the rate of instrumental deliveries was decreased in accompanying with the shortening of the analgesic duration at different cervical groupings.

The oral temperature was detected during analgesia recommended by Banerjee that oral temperature is a preferred routine detection of maternal pyrexia in labor for its positive correlation with intrauterine temperature (30). Our data are in line with other published results that women receiving EA had a significant increase in temperature after about five hours of analgesia (31). The longer the analgesia lasted, the more women experienced high oral temperature > 38 Celsius degree.

Nausea and vomiting are main side effects of gastrointestinal tract influenced by the pregnancy (32). In the present study the subjects evidenced more incidences of nausea and pruritus while the EA delivered at smaller cervical dilation, during which longer analgesia lasted. This is likely to be from a longer epidural analgesia re- sults in a relative larger dose of lipophilic opioid was absorbed into blood.

Given only one infant was delivered in at the cervix $\leq 10.0 \mathrm{~mm}$ group, so the analyses were processed in the infant outcomes statistics with the exclusion of this group. The oneminute and five-minute Apgar scores were similar amongst the other three groups. This expressed EA does not exert significant influence on neonatal Apgar ratings. The results of umbilical-cord blood gases measurement were in agreement with Wong's data (10). Goetzl et al. found EA could increase the rate of neonatal sepsis in afebrile women, in which the rate was $20.4 \%$ (23). Nonetheless, we did not find convincing evidence that EA performed early or late in labor increase the rate of neonatal sepsis. According to the report of Fisler et al., neonates received more diagnostic or therapeutic administration of antibiotics in those whose mothers received EA for pain relief during labor than infants born after an elective CS (33). The neonatal antibiotic treatment, in the present study, was similar to aforementioned report (approximately $10 \%$ ).

Additional analyses were performed to clarify the correlation amongst maternal characteristics and the risk of CS. Our results were consistent that maternal age at delivery, BMI, gestational age at birth and induced labor are significantly associated with the risk of Cesarean delivery $(10,34)$, but the smoking status is not related with the CS rate. These indicate that maternal characteristics are additional predictors for Cesarean during EA in labor.

\section{Limitations}

The study merely investigated the nulliparous women with single and vertex presentation, but whether such results could be applied to other populations were not guaranteed. Another question is the difficulty in blinding the study groupings from the obstetricians who ultimately made the decision for Cesarean delivery. We monitored the fetal heart-rate as a possible indicator for emergency $\mathrm{CS}$, though; the association amongst EA, fetal heart-rate variability and Cesarean delivery was not analyzed. In our study, the occurrence of an unfavorable fetal heart-rate in studying groups are similar (data are not shown). During enrolling subjects, we did not randomly assign the patients into groups; this is a methodological drawback of this trial.

\section{Conclusions}

When the EA was used in controlling labor pain, cervical dilation is a major aspect needed to be concerned. Cervical dilation $\leq 10.0 \mathrm{~mm}$ is a risk threshold in resulting in intrapartum Cesarean delivery, but the cervix > $10.0 \mathrm{~mm}$ is safety window for epidural placement without increasing the rate of Cesarean delivery in nulliparous women at term with vertex presentation. In addition, the maternal age at delivery and BMI, gestational age at labor and induced labor are confounding factors in influencing the CS rate while using EA. Further research is required to determine whether other patient groups are also likely to fit in such treatment.

\section{Acknowledgement}

We are indebted to all obstetricians, midwives, pediatricians, nurses and anesthesiologists who participated in collecting the data in our hospital.

\section{Funding}

This work was supported in part by the grants of National Natural Scientific Foundation of China (NSFC, 81271242 and 81371248), Nanjing Municipal Outstanding Young Scientist Grant, China (JQX12009) and Nanjing Municipal Youth Grants of Medical Science (QYK11139).

\section{Conflict of Interests}

None

\section{References}


1. Findley I, Chamberlain G. ABC of labor care: Relief of pain. BMJ 1999;318:927-30.

2. Leighton BL, Halpern SH. The effects of epidural analgesia on labor, maternal and neonatal outcomes: A systematic review. Am J Obstet Gynecol 2002;186:S69-77.

3. Marucci M, Fiore T. Epidural analgesia for labor and delivery: Current evidence. Minerva Anestesiol 2004;70:643-50.

4. Bucklin BA, Hawkins JL, Anderson JR, Ullrich FA. Obstetric Anesthesia Workforce Survey: Twenty-year update. Anesthesiology 2005;103:645-53.

5. Ji X, Qi H, Liu A. Clinical study on labor pain relief using the combined spinal-epidural analgesia and inhaling nitrous oxide. Zhonghua Fu Chan Ke Za Zhi 2002;37:398-401.

6. Wu CY, Ren LR, Wang ZH. Effects of epidural ropivacaine labor analgesia on duration of labor and mode of delivery. Zhonghua Fu Chan Ke Za Zhi 2005;40:369-71.

7. Xu SQ, Shen XF, Yuan HM. Epidural analgesia with ropivacaine during latent phase of labor. Zhongguo Fu You Bao Jian 2006;21:3035-6.

8. Fan ZT, Gao XL, Yang HX. Popularizing labor analgesia in China. Int J Gynaecol Obstet 2007;98:205-7.

9. Goetzl LM. ACOG Practice Bulletin no. 36: clinical management guidelines for obstetriciangynecologists: obstetric analagesia and anesthesia. Obstet Gynecol 2002;100:177-91.

10.Wong CA, Scavone BM, Peaceman AM, McCarthy RJ, Sullivan JT, Diaz NT, Yaghmour E, Marcus RJ, Sherwani SS, Sproviero MT, Yilmaz M, Patel R, Robles C, Grouper S. The risk of Cesarean delivery with neuraxial analgesia given early versus late in labor. N Engl J Med 2005;352:655-65.

11. American College of Obstetricians and Gynecologists, Committee on Obstetric Practice: ACOG Committee Opinion n. 339, June 2006: Analgesia and Cesarean delivery rates. Obstet Gynecol 2006;107:1487-8. Gu X; Labor Analgesia Examining
Group. Epidural analgesia in the latent phase of labor and the risk of cesarean delivery: a five-year randomized controlled trial. Anesthesiology 2009;111:871-80.

13. Liu EHC, Sia ATH: Rates of Cesarean section and instrumental vaginal delivery in nulliparous women after low concentration epidural infusions or opioid analgesia: Systematic review. BMJ 2004;328:1410-20.

14.Anim-Somuah M, Smyth R, Howell C. Epidural versus non-epidural or no analgesia in labor. Cochrane Database Syst Rev 2005;4:CD000331.

15. Marucci M, Cinnella G, Perchiazzi G, Brienza N, Fiore T. Patientrequested neuraxial analgesia for labor: impact on rates of Cesarean and instrumental vaginal delivery. Anesthesiology 2007;106:1035-45.

16. National Collaborating Centre for Women's and Children's Health. Intrapartum care-care of healthy women and their babies during childbirth. NICE Clinical Guideline 55, Royal College of Obstetricians and Gynaecologists (RCOG) Press, 2007:1-294.

17. National Collaborating Centre for Women's and Children's Health. Induction of labor. NICE Clinical Guideline 70, Royal College of Obstetricians and Gynaecologists (RCOG) Press, 2008:1-104.

18. Seyb ST, Berka RJ, Socol ML, Dooley SL. Risk of Cesarean delivery with elective induction of labor at term in nulliparous women. Obstet Gynecol 1999;94:600-7.

19.Luthy DA, Malmgren JA, Zingheim RW. Cesarean delivery after elective induction in nulliparous women: the physician effect. Am J Obstet Gynecol 2004;191:1511-5.

20. Vrouenraets FP, Roumen FJ, Dehing CJ, van den Akker ES, Aarts MJ, Scheve EJ. Bishop score and risk of Cesarean delivery after induction of labor in nulliparous women. Obstet Gynecol 2005;105:690-7.

21.Clark SL, Belfort MA, Hankins GDV, Meyers JA, Houser FM. Variation in the rates of operative delivery in the United States. Am J Obstet Gynecol 2007;196:526.e1526.e5.

22.Pernoll ML. Benson \& Pernoll's
Handbook of Obstetrics \& Gynecology. In: Course and conduct of labor and delivery. New York: McGraw-Hill. 2001:156-8.

23. Goetzl L, Cohen A, Frigoletto F Jr, Ringer SA, Lang JM, Lieberman E. Maternal epidural use and neonatal sepsis evaluation in afebrile mothers. Pediatrics 2001;108:1099-102.

24.Chestnut DH, Vincent RD Jr, McGrath JM, Choi WW, Bates JN. Does early administration of epidural analgesia affect obstetric outcome in nulliparous women who are receiving intravenous oxytocin? Anesthesiology 1994;80:1193-200.

25. Chestnut DH, McGrath JM, Vincent RD Jr, Penning DH, Choi WW, Bates JN, McFarlane C. Does early administration of epidural analgesia affect obstetric outcome in nulliparous women who are in spontaneous labor? Anesthesiology 1994;80:1201-8.

26. Gambling DR, Sharma SK, Ramin SM, Lucas MJ, Leveno KJ, Wiley J, Sidawi JE. A randomized study of combined spinal-epidural analgesia versus intravenous meperidine during labor: impact on Cesarean delivery rate. Anesthesiology 1998;89:1336-44.

27. Kotaska AJ, Klein MC, Liston RM. Epidural analgesia associated with low-dose oxytocin augmentation increases Cesarean births: a critical look at the external validity of randomized trials. Am J Obstet Gynecol 2006;194:809-14.

28. Comparative Obstetric Mobile Epidural Trial (COMET) Study Group UK. Effect of low-dose mobile versus traditional epidural techniques on mode of delivery: a randomized controlled trial. Lancet 2001;358:19-23.

29. Wilson MJ, Cooper G, MacArthur C, Shennan A; Comparative Obstetric Mobile Epidural Trial (COMET) Study Group UK. Randomized controlled trial comparing traditional with two "mobile" epidural techniques: anesthetic and analgesic efficacy. Anesthesiology 2002;97:1567-75.

30.Banerjee S, Cashman P, Yentis SM, Steer PJ. Maternal temperature monitoring during labor: concordance and variability among monitoring sites. Obstet Gynecol 
2004;103:287-93.

31.Camann WR, Hortvet LA, Hughes

$\mathrm{N}$, Bader AM, Datta S. Maternal temperature regulation during extradural analgesia for labor. $\mathrm{Br} \mathrm{J}$ Anesth 1991;67:565-8.

32. Einarson A, Maltepe C, Boskovic $\mathrm{R}$, Koren $\mathrm{G}$. Treatment of nausea and vomiting in pregnancy: an updated algorithm. Can Fam Physician 2007;53:2109-11.

33. Fisler RE, Cohen A, Ringer SA, Lieberman E. Neonatal outcome after trial of labor compared with elective repeat Cesarean section. Birth 2003;30:83-8.
34.Smith GC, Celik E, To M, Khouri $\mathrm{O}$, Nicolaides KH; Fetal Medicine Foundation Second Trimester Screening Group. Cervical length at mid-pregnancy and the risk of primary Cesarean delivery. $\mathrm{N}$ Engl J Med 2008;358:1346-53..

\section{APPENDIX I}

\section{Obstetric Oxytocin Infusion}

1. Prerequisites for oxytocin:

With one-to-one chaperonage to parturients;

Adequate intravenous solution;

Available of micro-infusion pump for precise administration of oxytocin;

Fetal-heart monitor at least 20 min prior to oxytocin;

Gestational age $\geq 41^{+0}$ weeks;

With favorable cervical dilation assessed with Bishop Score.

2. Indications for oxytocin infusion:

Pemature rupture of membranes;

Postterm pregnancy;

Significant fetal growth restriction;

Non-reassuring fetal surveillance;

Maternal conditions including diabetes, renal disease, significant pulmonary disease, hypertension-gestational, etc.;

Suspected or proven chorioamnionitis, abruption, and fetal death;

Patients' request (in special conditions).

3. Procedures for oxcytocin use:

Initial dose of oxytocin $0.5-1.0 \mathrm{mU} / \mathrm{min}$;

Increscent gradually $1.0-2.0 \mathrm{mU} / \mathrm{min}$ every $30-60 \mathrm{~min}$ till a maximal dose $20 \mathrm{mU} / \mathrm{min}$ reached or to ideal uterine contraction ( $3-4$ contractions in ten minutes, and lasting 90 sec or less with an interval of $30 \mathrm{sec}$ );

Generally, oxytocin $10 \mathrm{U}$ dissolved into 1,000 ml Ringer's solution, and titrated with the rate of $1.0 \mathrm{mU} / \mathrm{min}$.

4. Matters need attention during oxytocin infusion:

Continuous monitors of fetal-heart rate and uterine contraction;

Maintained if contraction reached ideal state;

If excessive uterine activity occurs (i.e. more than six contractions in two consecutive 10 min or contractions lasting longer than $120 \mathrm{sec}$ ), then:

1) Stop oxytocin use further;

2) Reposition the women in right or left lateral side;

3) Oxygen $10 \mathrm{l} / \mathrm{min}$ by face mask;

4) Maternal circulation evaluation;

5) Increase in intravenous hydration if appropriate;

6) Pelvic examination to rule out cord prolapsed;

7) Cervical dilation assessment;

8) Cesarean preparation if without recovery of fetal-heart rate;

If intrauterine resuscitation successes, oxytocin can be reused at the initial dose of half the last dosage before resuscitation;

In preventing postpartum uterine inertia, additional oxytocin $10 \mathrm{U}$ administered intramuscularly or $20 \mathrm{U}$ in $1,000 \mathrm{ml}$ Ringer's solution titrated with the rate of $100-125 \mathrm{ml} / \mathrm{h}$ at least one hour. 


\section{APPENDIX II}

\section{Standard Obstetric Care Procedures}

1. Procedures on parturients care in delivery suite:

Cervical examination at an interval of $30-60 \mathrm{~min}$;

Monitoring the fetal heart rate;

Maternal vital signs and uterine contraction monitor;

Maternal fluid management;

Oxygen provided with a nasal cannula;

Oxytocin titrated as appropriate with a favorable cervix condition;

Doula support;

Measuring the pain intensity with Visual Analog Scale (VAS) system;

Labor pain control at request including systemic or neuraxial analgesia;

Timely instrumental or Cesarean deliveries.

2. Indications for Cesarean section:

Malpresentation or malposition;

Fetal distress or premature rupture of membrane;

Placenta previa or placental abruption;

Uterine atony or metryperkinesis;

Abnormal amniotic fluid;

Mother-to-child transmission of maternal infections;

Abnormality of parturient canal including pelvic and genital tract;

Abnormality of umbilical cord including presentation, prolapse, torsion and entanglement;

Without any improvement after careful treatment of the abnormality of fetus and force of labor;

Severe obstetric complications (Hemorrhage, Convulsions, etc.);

Cessation of cervical dilation;

Arrest of fetal descent.

3. Indications for instrument-assisted delivery:

Fetal distress;

Delay in the second stage of labor;

Suspicion of immediate or potential fetal compromise in the second stage of labor;

Maternal indications include exhaustion, bleeding, cardiac or pulmonary disease, and history of spontaneous pneumothorax;

Fetal malposition including the after-coming head in breech vaginal delivery.

4. Prerequisites for instrumental delivery:

Fully dilated and retracted cervix;

Engaged head;

Ascertained position of the head;

No cephalopelvic disproportion beforehand assessment;

With ruptured membranes;

Adequate maternal analgesia;

Available facilities and supportive elements;

With competent operator. 